\title{
PERCEPÇÃO DOS ALUNOS DE ENSINO MÉDIO SOBRE EDUCAÇÃO AMBIENTAL, EM TEFÉ (AM)
}

\author{
Jomara Cavalcante de Oliveira ${ }^{1}$ \\ Aline Cristina Aparício Ramos ${ }^{2}$ \\ Kellen Queiroz Teixeira ${ }^{2}$ \\ Maria Gecineide Peres ${ }^{2}$ \\ Wanderson de Oliveira Carvalho
}

RESUMO: A educação e percepção ambiental despontam como armas na defesa do meio natural e ajuda a reaproximar o homem da natureza, garantindo um futuro com mais qualidade de vida para todos, já que desperta uma maior responsabilidade e respeito dos indivíduos em relação ao ambiente em que vivem. Este trabalho tem como objetivo avaliar o nível de percepção dos alunos de ensino médio ( $1^{\circ}$ e $2^{\circ}$ ano) sobre a Educação Ambiental. Para a coleta dos dados utilizou-se um questionário com dez perguntas. A pesquisa foi realizada com 70 alunos de uma escola com ensino médio em Tefé (AM). A partir da análise das respostas pode-se constatar que o meio ambiente é percebido pelos alunos de diferentes formas, englobando os aspectos bióticos, abióticos e sociais. Há uma grande preocupação por parte dos estudantes com a degradação ambiental que vem ocorrendo em sua cidade.

Palavras-chave: Percepção Ambiental; Meio Ambiente; Estudantes.

${ }^{2}$ Graduados em Ciências Biológicas pela Universidade do Estado do Amazonas.

Revbea, Rio Grande, V. 8, N 1:130-138, 2013. 


\section{INTRODUÇÃO}

Percepção ambiental pode ser definida como sendo uma tomada de consciência do ambiente pelo homem, ou seja, o ato de perceber o ambiente que se está inserido, aprendendo a proteger e a cuidar do mesmo (FERNANDES et al, 2005, p.1). O que se denomina de natureza ou mesmo meio ambiente é um conjunto de elementos vivos e não-vivos que constituem o planeta Terra. Todos esses elementos relacionam-se influenciando e sofrendo influência entre si, em um equilíbrio dinâmico (GUIMARÃES, 1995, p. 11).

Cada indivíduo percebe, reage e responde diferentemente às ações sobre o ambiente em que vive. As respostas ou manifestações daí decorrentes são resultado das percepções (individuais e coletivas), dos processos cognitivos, julgamentos e expectativas de cada pessoa (FERNANDES et al, 2005, p. 1).

Segundo Guimarães (1995, p.12),

nas sociedades atuais o ser humano afasta-se da natureza. A individualização chegou ao extremo do individualismo. O ser humano, totalmente desintegrado do todo, não percebe mais as relações de equilíbrio da natureza. Age de forma totalmente desarmônica sobre 0 ambiente, causando grandes desequilíbrios ambientais. O mundo é superpovoado e as cidades substituem com seus atrativos artificiais a beleza natural e o homem corre risco de sufocar-se em seu próprio lixo.

Ao longo dos últimos anos, a Educação Ambiental tem sido cogitada e adotada como fomentadora de ações capazes de colaborar na transformação do padrão de degradação socioambiental vigente. A escola foi um dos primeiros espaços a absorver esse processo de ambientalização da sociedade, recebendo sua cota de responsabilidade para melhorar a qualidade de vida da população, por meio de informação e conscientização (SEGURA, 2001, p.20).

Para Reigota (1998, p.43), a educação ambiental na escola ou fora dela continuará a ser uma concepção radical de educação, não porque prefere ser a tendência rebelde do pensamento educacional contemporâneo, mas sim porque nossa época e nossa herança histórica e ecológica exigem alternativas radicais, justas e pacíficas.

Leff (2005, p.246) afirma que a aprendizagem é um processo de produção de significações e uma apropriação subjetiva de saberes. Neste sentido, o processo educacional auxilia a formação de novos atores sociais, capazes de conduzir a transição para um futuro democrático e sustentável.

Com os problemas ambientais que vem afetando os diferentes meios ambientes (casa, escola, natureza, etc.) dia após dia, sentiu-se a necessidade de um diálogo mais profundo sobre o que os alunos entendem sobre a 
educação ambiental, o que percebem no seu cotidiano e o que podem mudar obtendo uma postura que contribua na construção de um meio ambiente melhor. Com esse tema traz-se a preocupação em relação ao meio ambiente, da necessidade que cada ser humano tem de fazer a sua parte. O presente trabalho tem por objetivo avaliar o nível de percepção dos alunos de ensino médio $\left(1^{\circ}\right.$ e $2^{\circ}$ ano) sobre a Educação Ambiental, motivando-os a pensarem sobre a importância do meio ambiente e relacioná-lo à realidade que vivenciam no dia a dia.

\section{METODOLOGIA}

A cidade de Tefé é o município polo da região do Triângulo Jutaí Solimões - Juruá é a cidade com maior numero de Instituições Educacionais da região possuindo universidades, centros técnicos e grande rede de escolas e instituições de ensino particulares. A pesquisa ocorreu em 2011, foi aplicada em uma escola com ensino médio que fica situado no município de Tefé (AM), em um período de quatro horas. Com a intenção de saber sobre a percepção ambiental dos alunos que são finalista nessa escola foram escolhidas duas turmas de ensino médio ( $1^{\circ}$ e $2^{\circ}$ ano) para responder um questionário contendo dez questões entre abertas e fechadas. Os alunos participantes possuíam idade média de 17 anos. O questionário foi elaborado e adaptado aos problemas ambientais presentes na área de estudo.

Desta forma realizou-se a pesquisa a partir do questionário, onde todos os dados obtidos foram anexados na planilha eletrônica do excel, seguidos pelas análises.

\section{RESULTADOS E DISCUSSÃO}

Setenta alunos participaram da pesquisa, sendo que $93 \%$ deles tinham entre 14 e 18 anos e apenas $7 \%$ tinham idade entre 19 e 23 anos. Entre esses $51 \%$ eram do sexo feminino e $49 \%$ do sexo masculino.

Os resultados obtidos permitiram avaliar o conhecimento dos alunos sobre Educação Ambiental. A primeira questão, "Para você, o que é meio ambiente?", revelou maneiras distintas de pensar, pois cada um apresentou sua própria definição (Figura 1).

Marques e Carniello (2010, p.343) demonstram resultados semelhantes com o encontrado nessa pesquisa, onde parte dos entrevistados raramente se considera membro do meio e sim um observador e explorador do mesmo, como mostrado anteriormente. 


\section{O que é meio ambiente?}

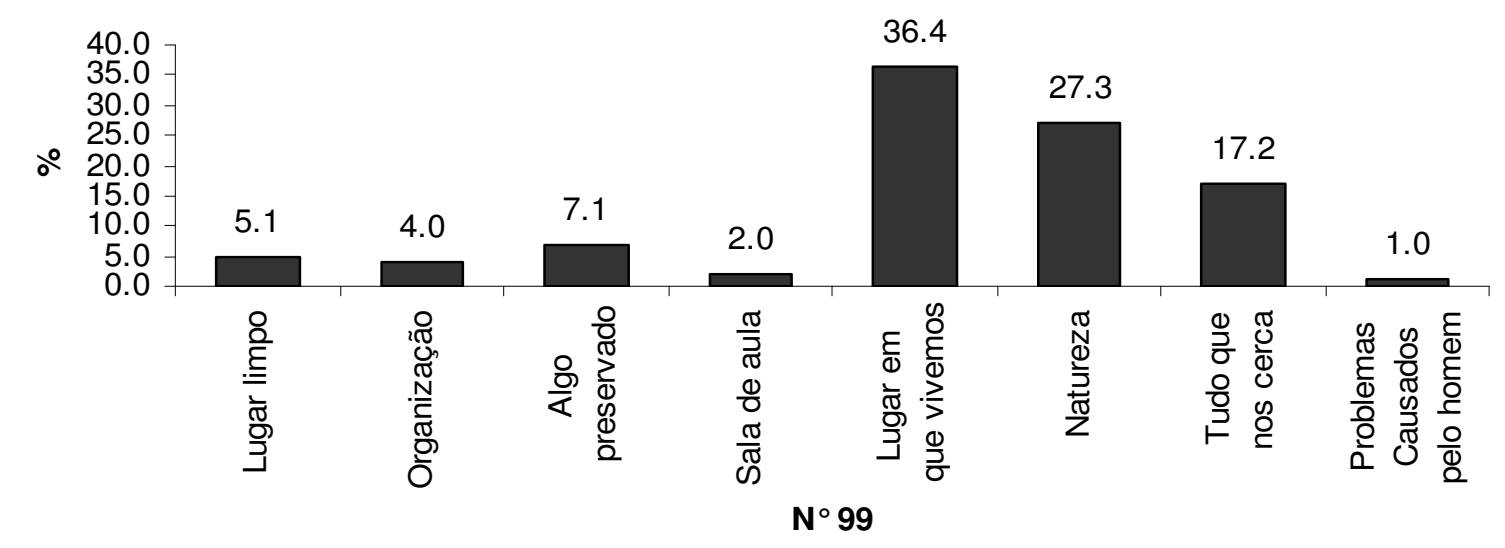

Figura 1: Respostas sobre "o que é meio ambiente".

Nas respostas à questão "No seu entender, o que são problemas ambientais?" pode-se observar que os entrevistados têm uma percepção clara sobre a referida questão (Figura 2).

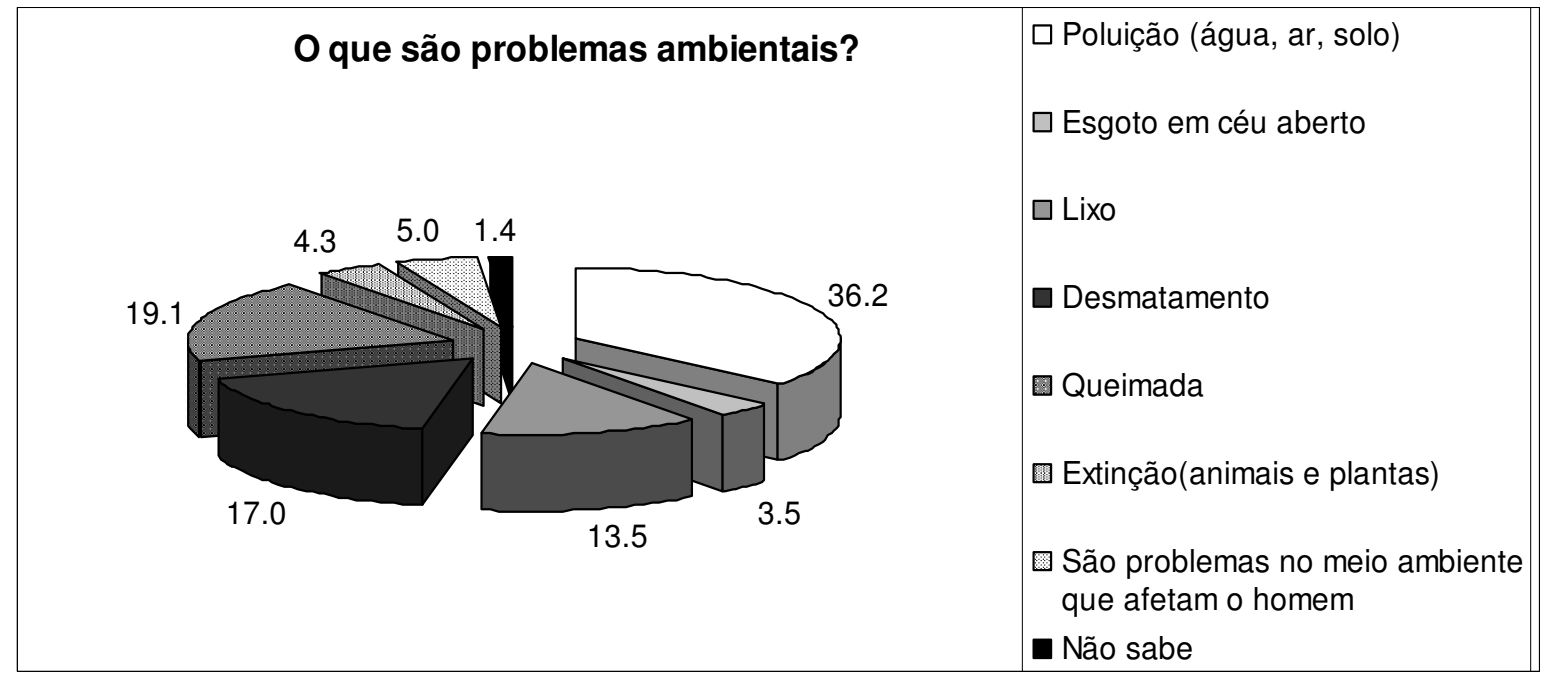

Figura 2: Participação dos entrevistados, sobre "o que são problemas ambientais".

A questão consecutiva "Você acha que existem problemas ambientais no Município de Tefé?", $100 \%$ dos alunos responderam que "Sim". Para a questão "Quais?", as respostas mais mencionadas foram "poluição" e "lixo", onde poluição obteve $31,3 \%$, "lixo" $29,4 \%$ e o terceiro problema mais citado foi "esgoto a céu aberto" com 15,3\%, (Figura 3). Percebeu-se ainda na análise dos textos, que os alunos têm uma grande preocupação com as condições de infraestrutura da cidade, especialmente quando citam os problemas de esgotos 
a céu aberto, a água do esgoto sem tratamento liberada no rio e o lixo espalhado nas ruas. Eles estão cientes das consequências oriundas desses problemas nas suas vidas e mesmo para a saúde. Segundo Elieldo J.C. (20 anos): "Os problemas ambientais em Tefé são o lixo, água poluída, desmatação como a queima de floresta, derrubadas de árvores que está acontecendo e com lixo vão gerar muitas doenças".

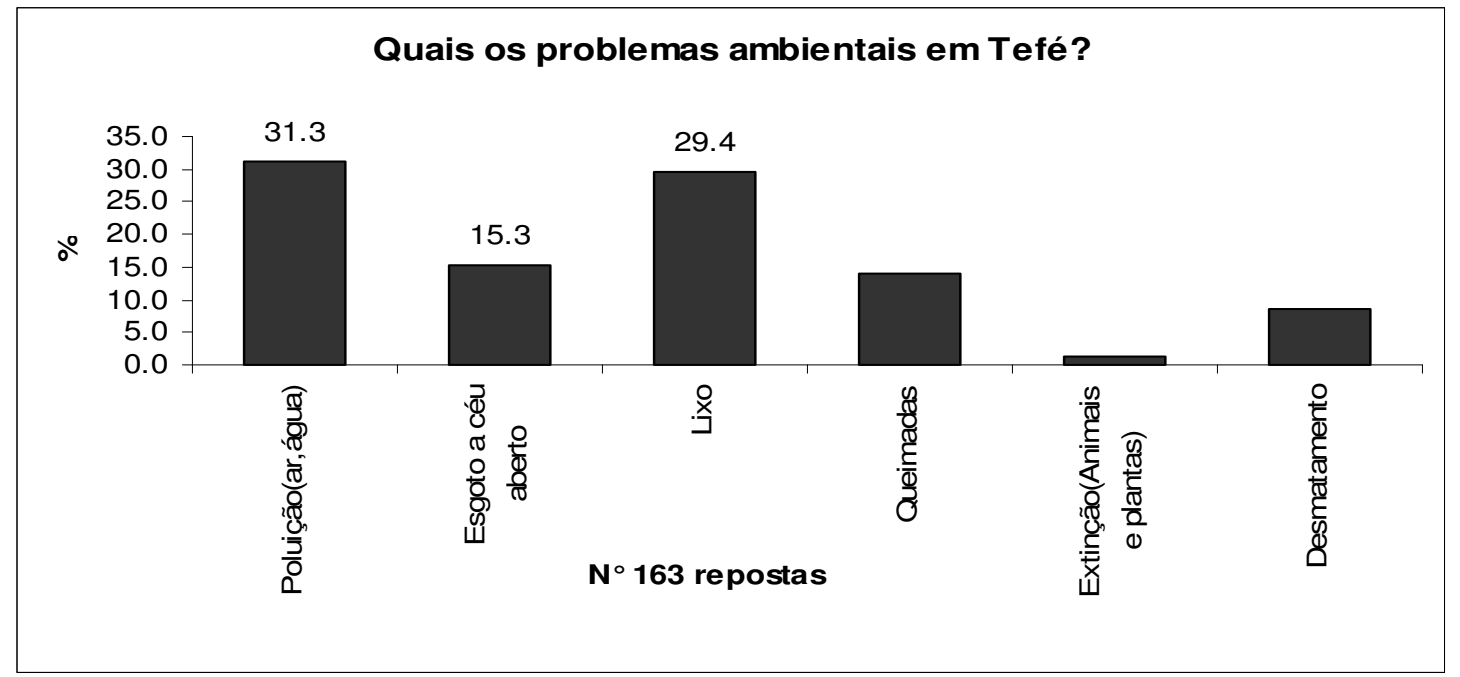

Figura 03: Participação dos entrevistados, sobre "quais os problemas ambientais em Tefé".

Questionados sobre "Quem são os responsáveis pelo surgimento dos problemas ambientais?", um pouco mais da metade dos alunos entrevistados responderam "nós mesmos" representando 53,5 \% das respostas, e 40,8 \% responderam que são "os homens", onde eles não se incluíam nesse item (Figura 4), como podemos perceber na resposta de Adriane S. B. (15 anos): "Os responsáveis são aqueles homens que poluem jogando lixo em toda parte, e a prefeitura por não poder dar mais recursos para o saneamento básico".

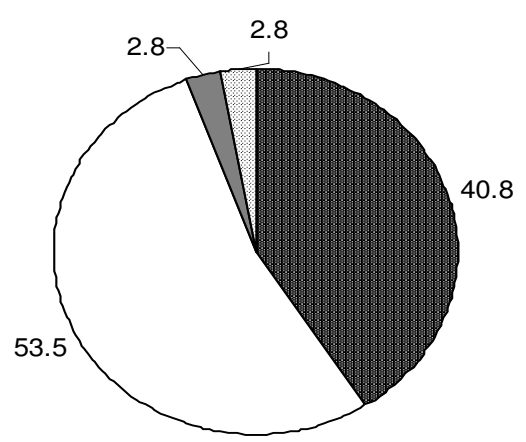

Figura 4: Participação dos entrevistados, sobre o "quem são os responsáveis pelo surgimento de problemas ambientais". 
Em uma das questões fechadas, pedimos aos alunos que marcassem os problemas ambientais seriíssimos na opinião deles. Mais uma vez "poluição das águas" foi à alternativa mais mencionada com $25 \%$ das opiniões, seguidas pelo "corte de árvores e queimadas" com $14 \%$ e a poluição causada pelos automóveis nas cidades como "Fumaças de carros, ônibus e caminhão" representaram também $14 \%$ das opiniões (Figura 5).

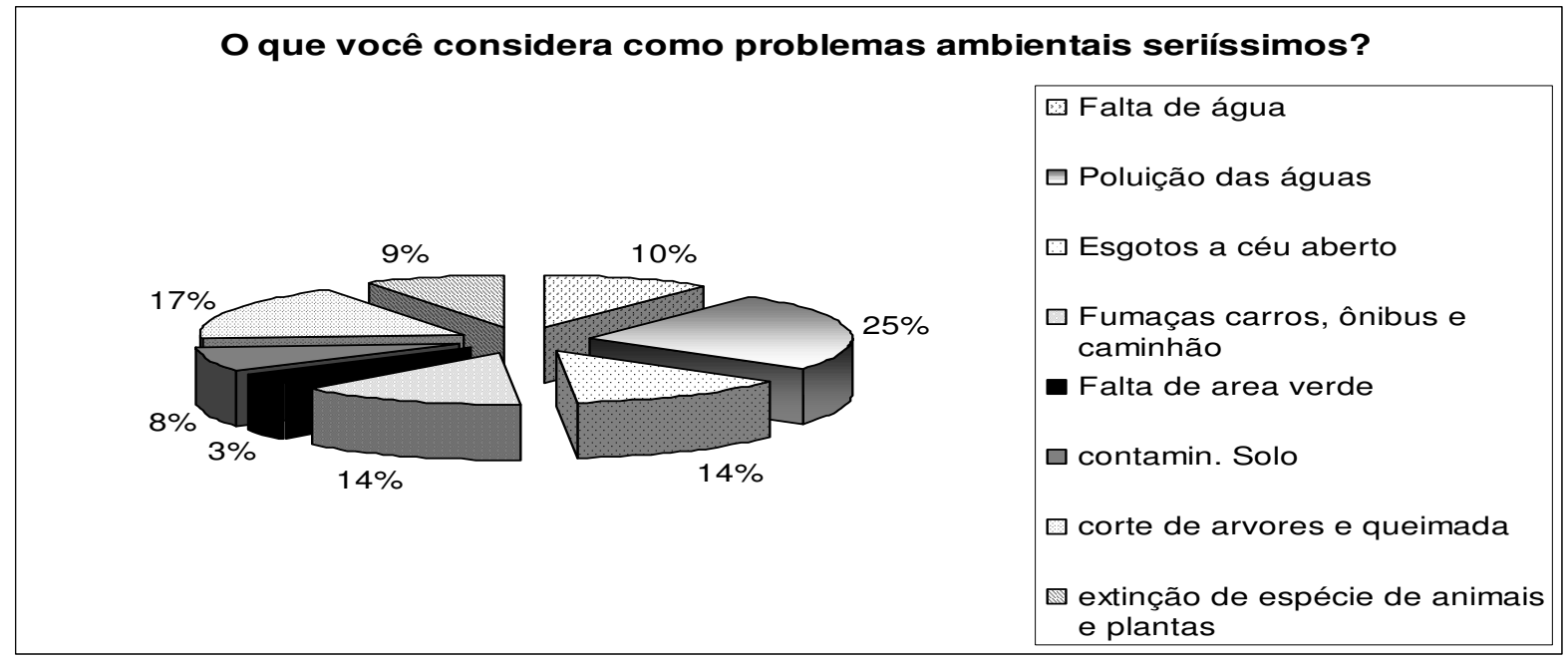

Figura 5: Participação dos entrevistados, sobre "o que você considera com problemas ambientais seriíssimos".

A pergunta que os questionava sobre "Como as pessoas podem melhorar o ambiente em que vivem?", foi encontrado valores distintos, onde 25,2 \% responderam "não poluir os rios" e 22,3 \% para "não queimar a floresta" e 18,8 \% para "separar o lixo" (Figura 6).

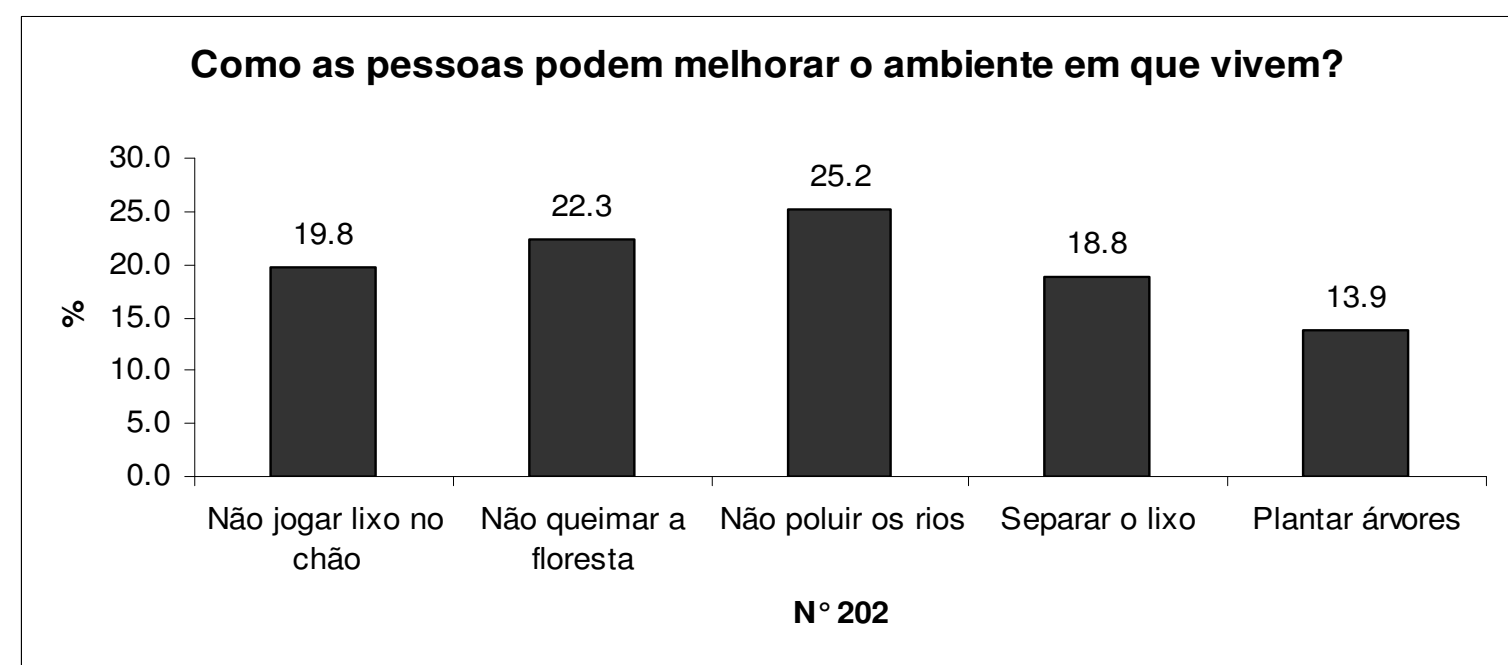

Figura 06: Participação dos entrevistados, sobre o "como as pessoas podem melhorar o ambiente em que vivem".

Revbea, Rio Grande, V. 8, N 1:130-138, 2013. 
Assim percebe-se que estes alunos estão preocupados com estas atitudes e acreditam que a conservação ambiental começaria com a recuperação destas áreas que são degradadas. Como afirma Marques \& Carniello (2003, p.11): "o homem é o responsável pela degradação ambiental, porém pode vir dele mesmo a proposta para a conservação".

Em relação à questão sobre "Quem deveria ajudar a resolver os problemas ambientais?", perceberam-se através das respostas que os alunos se mostraram bastante cooperativos, pois $41,4 \%$ das respostas corresponderam a "comunidade unida", seguida por $21,6 \%$ de "você individualmente" e 12,6 \% por "organizações ecológicas" (Figura 7).

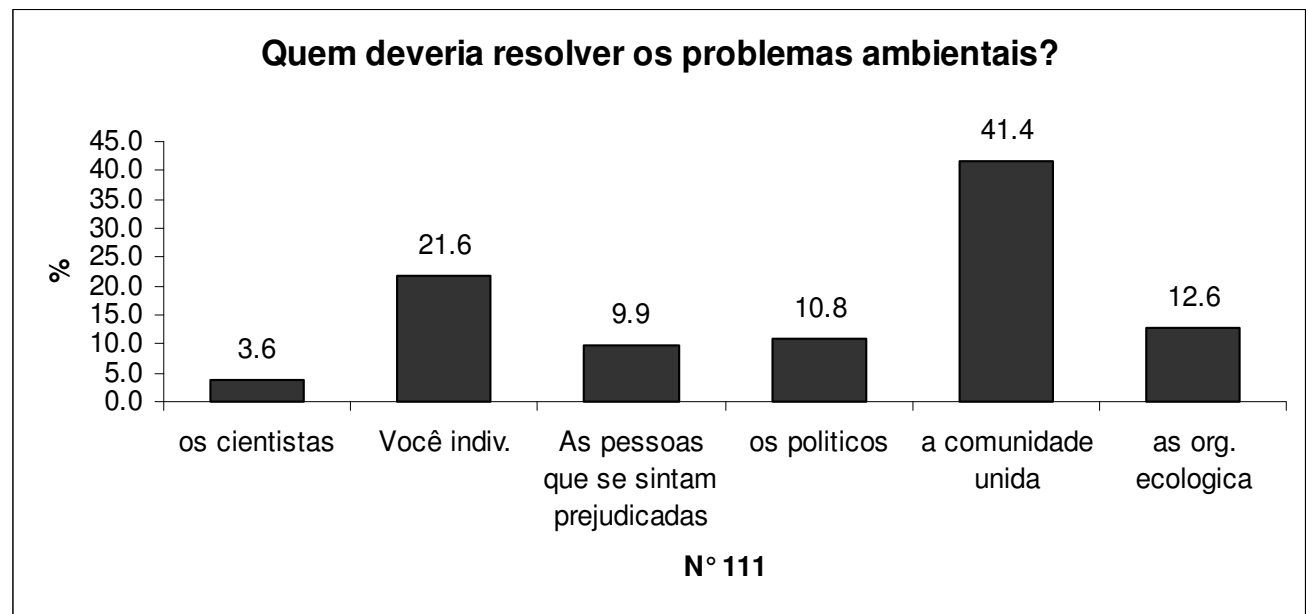

Figura 7: Participação dos entrevistados, sobre o "quem deveria resolver os problemas ambientais".

Para questão sobre quais os meios de informação que os entrevistados costumam ter sobre o meio ambiente, 40,9 \% responderam ser por meio da "televisão", 19,0 \% responderam ser pelos "professores" e 14,6 \% por meio de jornais impressos (Figura 8).

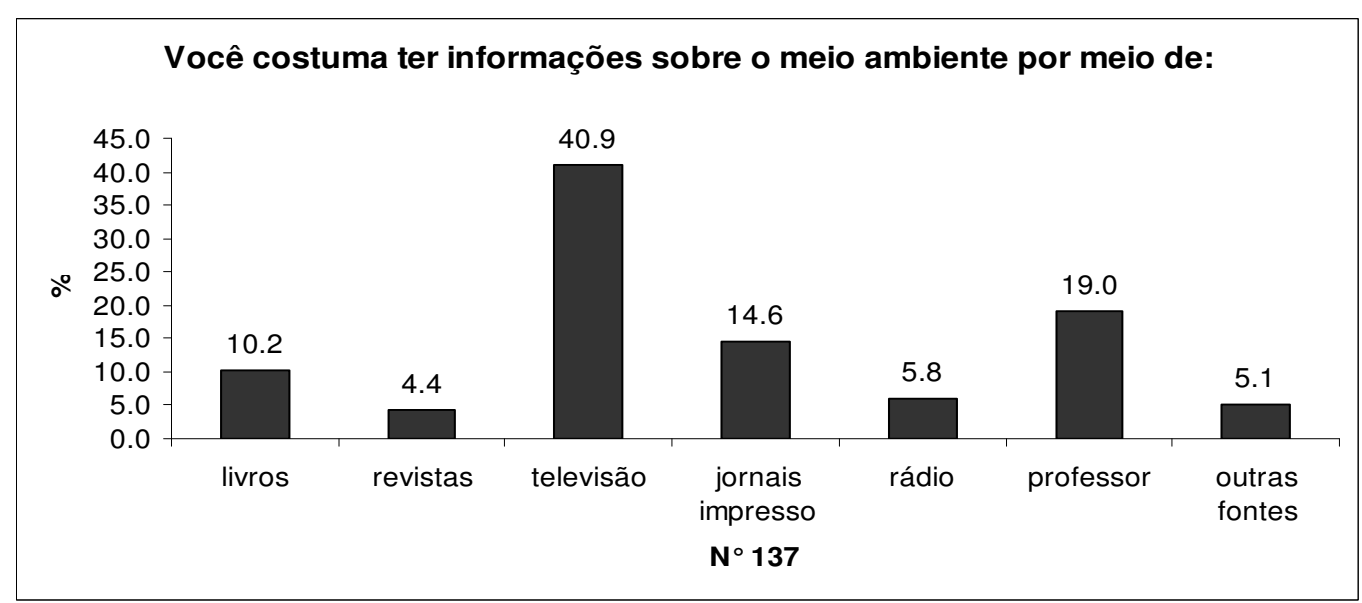

Figura 8: Participação dos entrevistados, sobre o quais meios que eles costumam ter informações sobre meio ambiente.

Revbea, Rio Grande, V. 8, N 1:130-138, 2013. 
De acordo com os resultados mostrados anteriormente, há que se pensar nos caminhos para que a educação ambiental se concretize nas escolas. Deve-se pensar em formas de discutir, desconstruir e reconstruir as representações dos professores e de todos os sujeitos envolvidos no processo educacional, sendo ele professor de ciência/biologia ou não.

Segundo Tuan (1980, p.06) "[...] por mais diversas que sejam as nossas percepções do meio ambiente, como membros da mesma espécie, estamos limitados a ver as coisas de uma certa maneira". Cada indivíduo percebe o ambiente à sua maneira, e esta percepção é de grande relevância para a conservação ambiental, pois é a partir dela que surgem as propostas para a realização de trabalhos desta natureza.

\section{CONCLUSÃO}

Com a realização desta pesquisa foi possível compreender que a temática ambiental deve ser trabalhada com maior frequência nas escolas, para que todos os alunos passem a perceber sua importância tanto na relação com o ambiente como também nas responsabilidades para a conservação deste. $\mathrm{Na}$ entrevista realizada constatou-se que os alunos ainda estão com dificuldades em perceber-se como parte integrante desse meio. Foi evidenciado no decorrer da pesquisa que os estudantes têm uma percepção clara dos problemas ambientais que os cercam.

\section{REFERENCIAS}

FERNANDES, R.S., PELISSARI, V.B., SOUZA, V.J. , Uso da percepção ambiental como instrumento de gestão educacional e ambiental, $23^{\circ}$ Anais do Congresso Brasileiro de Engenharia Sanitária e Ambiental, 2005.

GUIMARÃES, M. A dimensão ambiental na educação. Campinas- SP: Papirus, 1995.

LEFF, E. Saber ambiental: Sustentabilidade, Racionalidade, Complexidade, Poder. Petrópolis: Vozes, 2005.

MARCONI, M.A.; LAKATOS, E.M. Metodologia do Trabalho Científico, São Paulo. Ed. Atrás, 4aㅡ edição, 1992.

MARQUES, L. M.; CARNIELLO, M. A. Educação ambiental nos quintais uma articulação entre escola e comunidade. In: EPEA: abordagens epistemológicas e metodológicas, 2. São Carlos-SP. Gráfica Futura, 2003.

MARQUES, L.M.; CARNIELLO, M.A. A percepção ambiental como papel fundamental na realização de pesquisa em educação ambiental. Cascavel (PR), Travessias Ed. 10. Vol. 4, No 3 (2010). 
REIGOTA, M. Desafios à educação ambiental escolar. In: CASCINO, F.; JACOBI, P.; OLIVEIRA, J.F. (Orgs.). Educação, meio ambiente e cidadania. São Paulo: SMA/Ceam, 1998.

SEGURA, D.S. . Educação ambiental na escola pública: da curiosidade ingênua à consciência crítica. São Paulo: Annablume/FAPESP, 2001.

TUAN, YI-FU. Topofilia: um estudo da percepção, atitudes e valores do meio ambiente. São Paulo: DIFEL, 1980. 